\title{
A GCM study of the response of the atmospheric water cycle of West Africa and the Atlantic to Saharan dust radiative forcing
}

\author{
K. M. Lau ${ }^{1}$, K. M. Kim ${ }^{2}$, Y. C. Sud ${ }^{1}$, and G. K. Walker ${ }^{3}$ \\ ${ }^{1}$ Laboratory for Atmospheres, NASA/GSFC, Greenbelt, MD, USA \\ ${ }^{2}$ Goddard Earth Science Technology Center, UMBC, Baltimore, MD, USA \\ ${ }^{3}$ SAIC/General Sciences Operation, Beltsville, MD, USA
}

Received: 27 February 2009 - Revised: 25 September 2009 - Accepted: 10 October 2009 - Published: 23 October 2009

\begin{abstract}
The responses of the atmospheric water cycle and climate of West Africa and the Atlantic to radiative forcing of Saharan dust are studied using the NASA finite volume general circulation model (fvGCM), coupled to a mixed layer ocean. We find evidence of an "elevated heat pump" (EHP) mechanism that underlines the responses of the atmospheric water cycle to dust forcing as follow. During the boreal summer, as a result of large-scale atmospheric feedback triggered by absorbing dust aerosols, rainfall and cloudiness are enhanced over the West Africa/Eastern Atlantic ITCZ, and suppressed over the West Atlantic and Caribbean region. Shortwave radiation absorption by dust warms the atmosphere and cools the surface, while longwave has the opposite response. The elevated dust layer warms the air over West Africa and the eastern Atlantic. As the warm air rises, it spawns a largescale onshore flow carrying the moist air from the eastern Atlantic and the Gulf of Guinea. The onshore flow in turn enhances the deep convection over West Africa land, and the eastern Atlantic. The condensation heating associated with the ensuing deep convection drives and maintains an anomalous large-scale east-west overturning circulation with rising motion over West Africa/eastern Atlantic, and sinking motion over the Caribbean region. The response also includes a strengthening of the West African monsoon, manifested in a northward shift of the West Africa precipitation over land, increased low-level westerly flow over West Africa at the southern edge of the dust layer, and a near surface westerly jet underneath the dust layer over the Sahara. The dust radiative forcing also leads to significant changes in surface energy fluxes, resulting in cooling of the West African land and the eastern Atlantic, and warming in the West Atlantic and Caribbean. The EHP effect is most effective for mod-
\end{abstract}

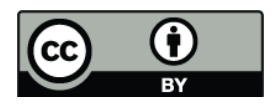

Correspondence to: K. M. Lau (william.k.lau@nasa.gov) erate to highly absorbing dusts, and becomes minimized for reflecting dust with single scattering albedo at 0.95 or higher.

Keywords. Atmospheric composition and structure (Aerosols and particles) - Meteorology and atmospheric dynamics (Precipitation; Radiative processes)

\section{Introduction}

The Saharan region is a major source of atmospheric dust. It has been estimated that over $50 \%$ of the total annual dust loading in the atmosphere, estimated at 2-4 billion tons globally, comes from the Saharan desert (Goudie and Middleton, 2001; Ginoux et al., 2001). Unlike aerosols from industrial pollution, which are mostly trapped within the stable, lowlevel atmospheric boundary layer, Saharan dusts are found in a much deeper boundary layer over the hot desert, and often are swept up by strong winds and lofted into the middle and upper troposphere. The elevated dust particles are transported thousands of kilometer from the source region across the entire Atlantic to the Caribbean, the southeastern US and elsewhere (Chin et al., 2007). Saharan dust might impact the climate and the water cycle of the entire West Africa, tropical Atlantic and the Caribbean (WAAC) region (Prospero and Lamb, 2003). The transport of Saharan dust and its impacts could extend far beyond the WAAC region, spreading to the Mediterranean, Eurasia and the North Pacific (Moulin et al., 1997; Kim et al., 2006).

Several general circulation model (GCM) studies have provided a reasonable understanding of the fundamental processes associated with direct radiative effects of dust on the earth's climate and water cycle. Miller and Tegen (1998) found that dust radiative effect may increase or decrease precipitation in different regions depending on whether deep

Published by Copernicus Publications on behalf of the European Geosciences Union. 
convection is present or not. Perlwitz et al. (2001) showed that dust emission, transport and climate forcing are highly sensitive to optical properties of dust, especially the absorption of solar radiation. In turn these parameters are strong functions of the dust sources and dust particle-evolutions while in transport. Miller et al. (2004) demonstrated that while global precipitation is reduced in response to surface radiative forcing of dust, precipitation may be enhanced locally over desert regions. Yoshioka et al. (2007) found that for weakly absorbing dust, rainfall is reduced globally as well as regionally, over the Sahel in response to dust radiative effects. They estimated that $\sim 30 \%$ of the observed precipitation reduction in the Sahel from the 1950-1960s to the 19701980s may be attributed to dust. Solmon et al. (2008) found using regional climate model that the precipitation response over West Africa to dust radiative forcing is highly sensitive to the radiative properties of dust. All the aforementioned results are consistent with the presence of an atmospheric heating component of dust aerosol forcing that enhances precipitation, and a surface cooling component that reduces precipitation. Exactly how these two components play out depends on the model physics, and the ambient large scale environment. In particular, atmospheric feedback processes associated with the regional meteorology of the WAAC, induced by dust radiative forcing are not well understood.

Recently, Lau et al. (2006) and Lau and Kim (2006) found that the radiative heating by elevated absorbing aerosols (dust and black carbon) accumulated over the southern slopes of the Himalayas can trigger a convective water cycle feedback that invigorates moist convection over northern India, and a subsequent intensification of the South Asian monsoon. They called this the "elevated heat pump" (EHP) effect. The authors further argued that EHP effect is an intrinsic response of the water cycle to aerosol radiative forcing in regions where there is an abundance of elevated absorbing aerosols, such as the WAAC.

In this paper, we focus on the impacts of dust radiative heating processes, on the large-scale circulation and latent heating feedbacks associated with the seasonal and regional climate of the WAAC. Specifically, we examine the plausible impacts of Saharan dust, and explore the relevance of the EHP mechanism to the climate states of the WAAC during the June-July-August (JJA) periods. Aerosol indirect effects are not included in the present simulations.

\section{Model description and experiment set-up}

We use the NASA fvGCM with the Microphysics with Relaxed Arakawa Schubert (McRAS), which includes state-ofthe-art prognostic cloud water schemes, and liquid- and icephase cloud microphysics (Sud and Walker, 1999, 2003), and radiative transfer scheme of Chou and Suarez $(1994,1999)$. The fvGCM GCM has a $2 \times 2.5$ degree resolution, 55 layers in the vertical and is coupled to the NCAR community land model (Dai et al., 2002) and a perturbation mixed layer ocean (MLO) model. The MLO model (Waliser et al., 1999) computes the daily perturbation from the prescribed monthly mean (interpolated to daily values) sea surface temperature (SST) based on the changes in surface fluxes and prescribed monthly climatology of ocean mixed layer depth (de Boyer Montegut et al., 2004). Global aerosol forcing is prescribed from monthly climatologies (interpolated to daily values) of four-dimensional datasets of each of the five aerosol species (dust, black carbon, organic carbon, sulfate and sea salt) derived from the Goddard Chemistry Aerosol Radiation Transport (GOCART) model (Chin et al., 2002, 2004). The GOCART dust model uses 8 particle sizes ranging from 0.1 to $10 \mu \mathrm{m}$, and a dust generating parameterization, which is a function of the surface wind, soil types and surface depression (Ginoux et al., 2001). The source functions for other aerosol species are prescribed from observed climatologies. The extinction coefficient $(\lambda)$, single scattering albedo $\left(\omega_{o}\right)$, and the asymmetric factor $(\mathrm{g})$ for each aerosol types are computed for 11 broad wavelength bands from Mie theory as a function of the ambient relative humidity. Both shortwave and longwave forcing are included. The aerosol distribution and their optical properties have been evaluated with in-situ and satellite observations over various sites and regions (Chin et al., 2002). The values of $\omega_{o}$ used in the model have a range from 0.8-.94 in the shortwave spectral range $(0.4-2.27 \mu \mathrm{m})$. While these $\omega_{o}$ values are lower than those used by Yoshioka et al. (2007) and Kaufman et al. (2001), but they are well within the range used in other studies (Tegen and Lacis, 1996; Miller et al., 2004). The sensitivity of our results to the optical properties of aerosols is examined in Sect. 3.4.

The simulations are intended to "tease out" the atmospheric water cycle feedback due to dust radiative effects, under the controlled condition of prescribed seasonally varying aerosol forcing. To increase statistical significance, we have carried out two sets of simulations, each containing 4member (each member starting from different initial conditions) integration with interactive SST and land processes, first with all aerosols (AA) as the control, and second with all aerosol radiation disabled (NA). Each experiments starts from 1 April and ends in 31 October for the 8-year period (2000-2007). Since the two sets of experiments are identical, except for the prescribed aerosols, significant differences in the ensemble mean between the AA and NA can be attributed to responses of the water cycle to aerosol radiative forcing.

\section{Results}

\subsection{Model climatology and aerosol forcing}

The control run (AA) simulates key features of the seasonal mean sea-level pressure, and large-scale circulation reasonably well with reference to the available analyses, 

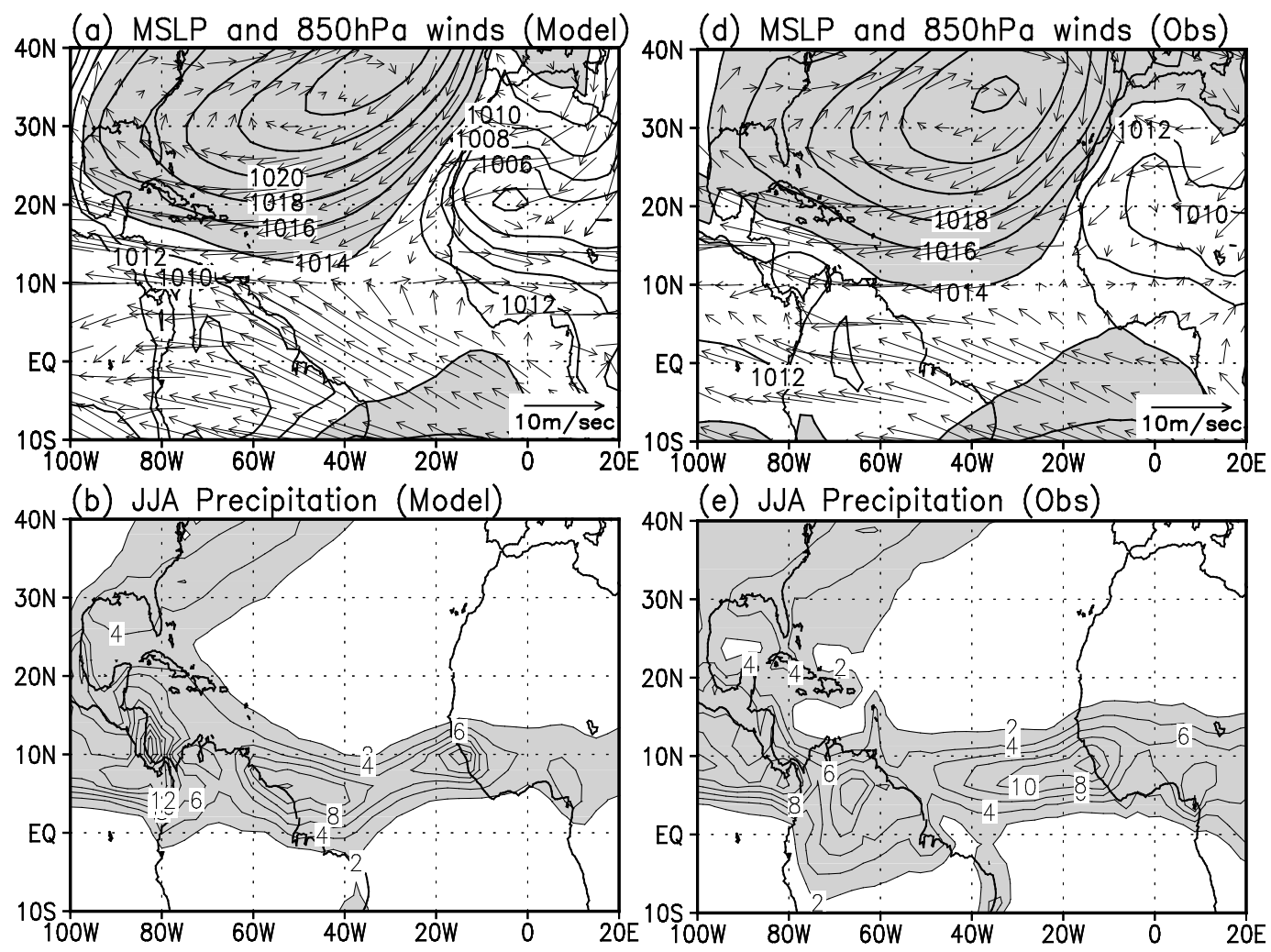

(e) JJA Precipitation (Obs)
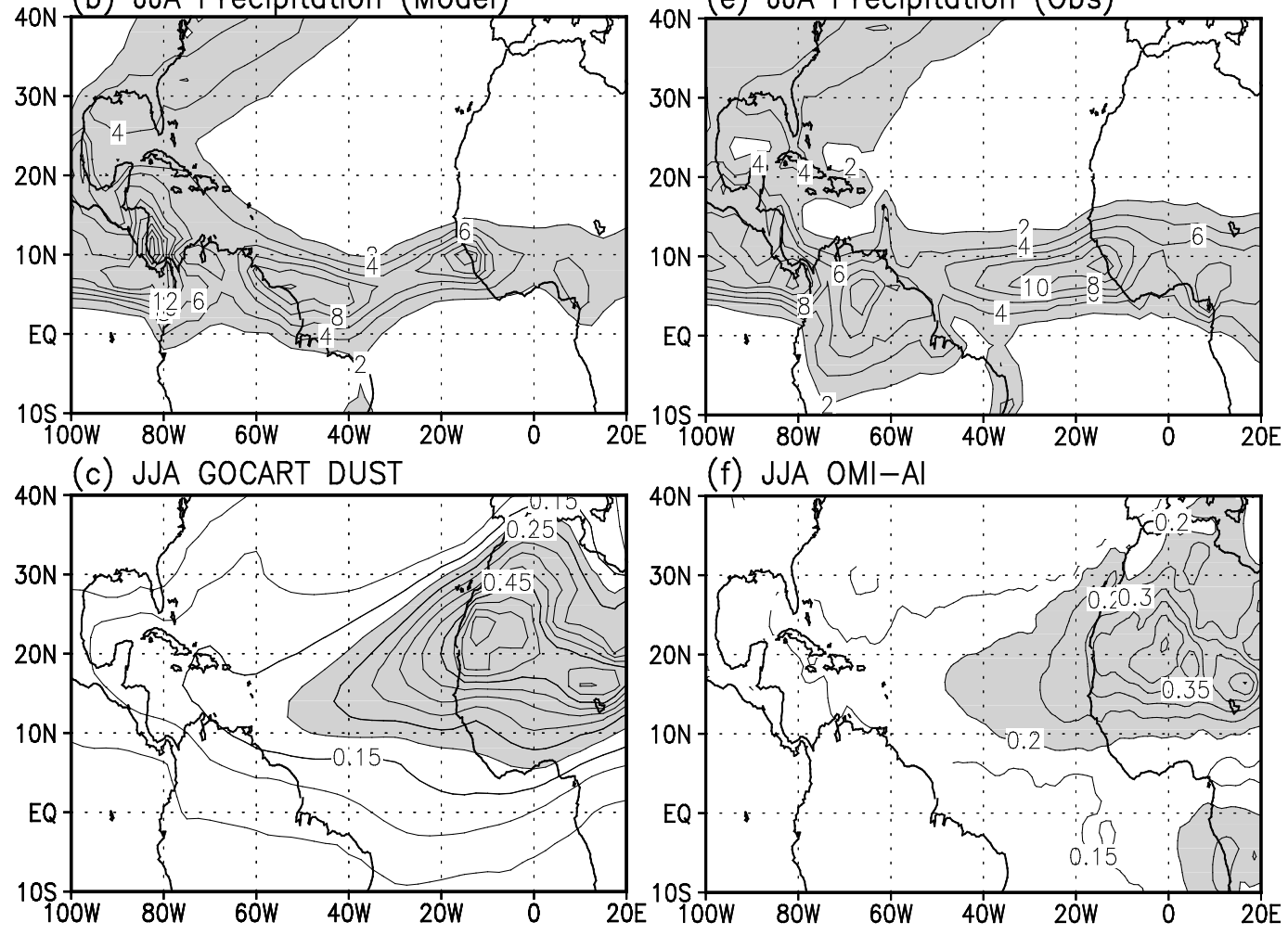

Fig. 1. JJA model climatology of (a) $850 \mathrm{hPa}$ wind $\left(\mathrm{ms}^{-1}\right)$ and mean sea level pressure (hPa), (b) rainfall (mm day ${ }^{-1}$ ) from control run (AA), compared with corresponding observation climatology from NCEP reanalysis and GPCP precipitation in (d) and (e). JJA mean dust aod from GOCART and TOMS-AI are shown in (c) and (f), respectively.

e.g., National Center for Environmental Prediction (NCEP). Specifically, at $850 \mathrm{hPa}$, these include the large-scale North Atlantic anticyclone, the heat low over North Africa, and the easterly trade wind zone at $0-25^{\circ} \mathrm{N}$, (Fig. 1a and d). The model rainfall patterns capture key features of the precipitation climatology available from the Global Precipitation Climatology Project (GPCP), including the Atlantic ITCZ and the West Africa monsoon rain belt, and rainfall over central and South America (Fig. 1b, e). However, these features show some model biases. The low-level westerly near 10$15^{\circ} \mathrm{N}$ associated with the West Africa Monsoon (WAM) is over-estimated compared to the observation. The model has a dry bias over eastern tropical Atlantic, the WAM land region, the African continent, especially over Sahel, and South America but overestimates rainfall over western tropical Atlantic Ocean and Caribbean. The impact of including aerosol in correcting these biases is discussed in the Appendix. More detailed comparison of the present model with observations and other models can be found in Xue et al. (2009). Some of discrepancies may be related to crude representation of topography, and land-sea contrast in the $2^{\circ} \times 2.5^{\circ}$ resolution GCM. The JJA-mean dust aerosol GOCART AOD 

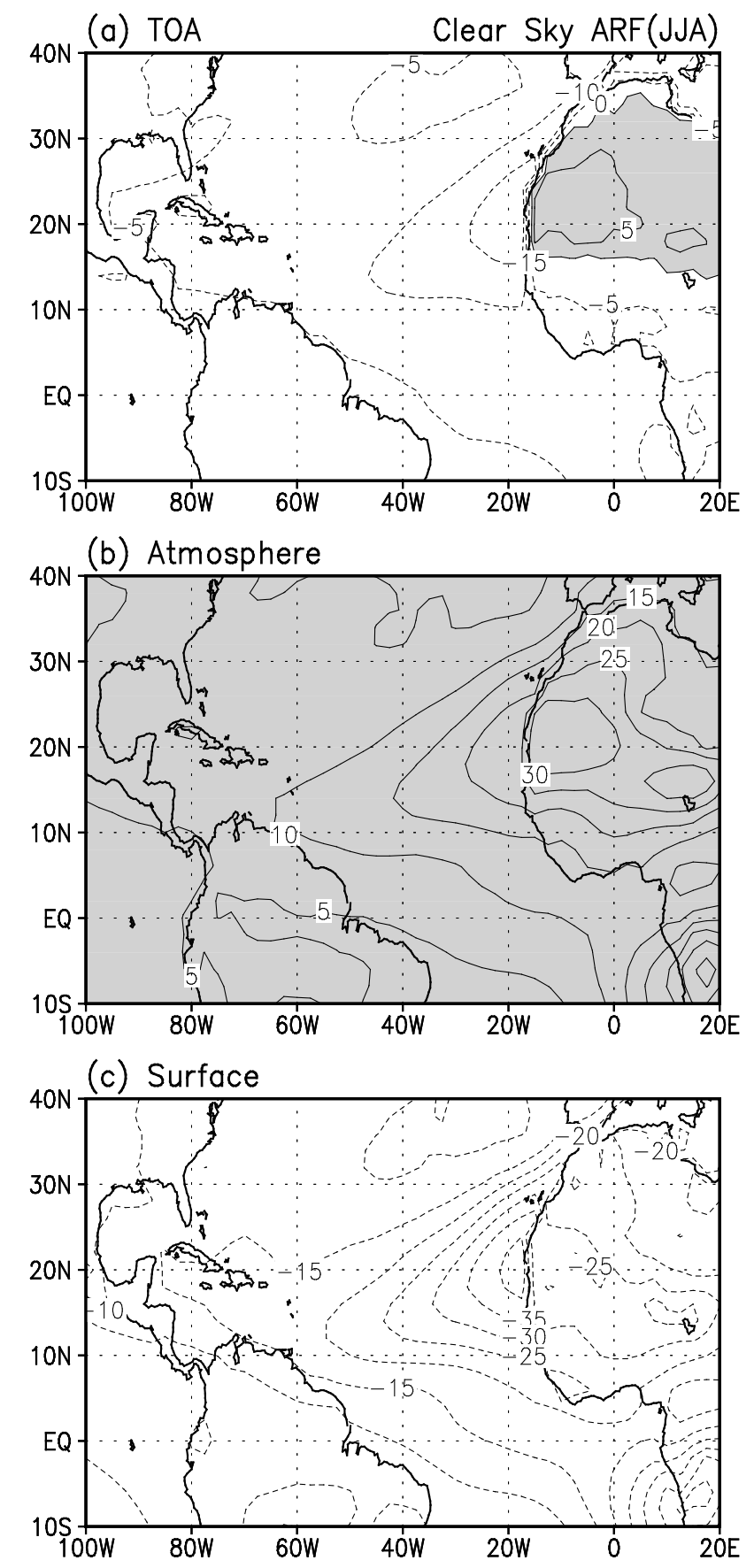

Fig. 2. Model simulated clear-sky aerosol radiative forcing $\left(\mathrm{W} \mathrm{m}^{-2}\right)$ at (a) top of atmosphere, (b) atmosphere, and (c) surface.

distribution (Fig. 1c) used in the model is also comparable to the estimated coarse mode AOD from the Ozone Monitoring Instrument (OMI) on the Aura satellite (Fig. 1f). The coarse mode AOD is derived from OMI aerosol index (AI) based on the regression between OMI AI and coarse mode AOD from MODIS/Aqua over ocean $(60 \mathrm{~W}-20 \mathrm{~W}, 5 \mathrm{~N}-30 \mathrm{~N})$ for boreal summers of 2004-2008. The OMI-AI is used, because it is
Table 1. Comparison of model areal mean radiative forcing of Saharan dust over the North Atlantic Ocean $\left(0-30^{\circ} \mathrm{N}, 50-20^{\circ} \mathrm{W}\right)$ with previous models and observations. TOA=top of atmosphere, ATM=atmosphere, and SFC=surface. Positive downward for TOA and SFC, positive for absorption in ATM. All dust optical thicknesses have been scaled to 0.20 . Unit is in $\mathrm{W} \mathrm{m}^{-2}$.

\begin{tabular}{lrrr}
\hline & SW & LW & Net \\
\hline Present model & & & \\
TOA & -7.0 & +0.8 & -6.2 \\
ATM & +9.5 & -1.1 & +8.4 \\
SFC & -16.5 & +1.9 & -14.6 \\
Yoshioka et al. (2007) & & & \\
TOA & -5.9 & +1.1 & -4.8 \\
ATM & +3.2 & -2.0 & +1.2 \\
SFC & -9.1 & +3.1 & -6.0 \\
Zhu et al. (2007) & & & \\
TOA & -9.3 & +5.4 & -3.9 \\
ATM & +5.5 & -0.3 & +5.2 \\
SFC & -14.8 & +5.7 & -9.1 \\
\hline
\end{tabular}

a direct measurement of absorbing aerosols (dust and black carbon), and has the capability of measuring aerosol signal over clouds and bright land surfaces. Comparing Fig. 1c and $1 \mathrm{f}$, the two main sources of dust emission, i.e., one near the west coast of the Sahara desert, near $\left[25^{\circ} \mathrm{N}, 15^{\circ} \mathrm{W}\right]$, and one near the Bodele Depression $\left[15^{\circ} \mathrm{N} 15^{\circ} \mathrm{E}\right]$, are well simulated (Middleton and Goudie, 2001; Jeong et al., 2008). Both observation and model show the extension of dust tongue, with the maximum dust zone tilted slightly southward from West Africa to the Caribbean. As expected, regions of heavy dust loading are collocated with region of light or absence of rainfall, having the maximum dust zone lies far north of the Atlantic ITCZ. In the region, $0-15^{\circ} \mathrm{N}$, dust and rainfall coexist, and may interact physically with each other (not considered in this work). Based on the concentration for different aerosol species from GOCART, more than $90 \%$ of AOD over the West Africa land region, and over $80 \%$ over the eastern tropical Atlantic are due to dust. The rest are 10-18\% due to sulfate and sea salt, and less than $2 \%$ from black carbon. Since sulfate and sea salt are non-absorbing aerosols and black carbon loading is very small during JJA, heating of the atmosphere in the experiment are almost entirely due to dust. Overall, the GOCART may have over-estimated the dust AOD by about $10-15 \%$, but is otherwise quite reasonable in simulating the seasonal variations of the emission and transport of Saharan dusts.

Figure 2 shows the simulated seasonal (JJA) mean of clearsky aerosol radiative forcing. The forcing is relatively small at the top-of-the-atmosphere (TOA) as compare to that at the surface and in the atmosphere; it indicates a slight warming of the atmosphere-land and cooling of the atmosphereocean center over the coast of West Africa (Fig. 2a). The relatively small TOA forcing stems from large compensation 

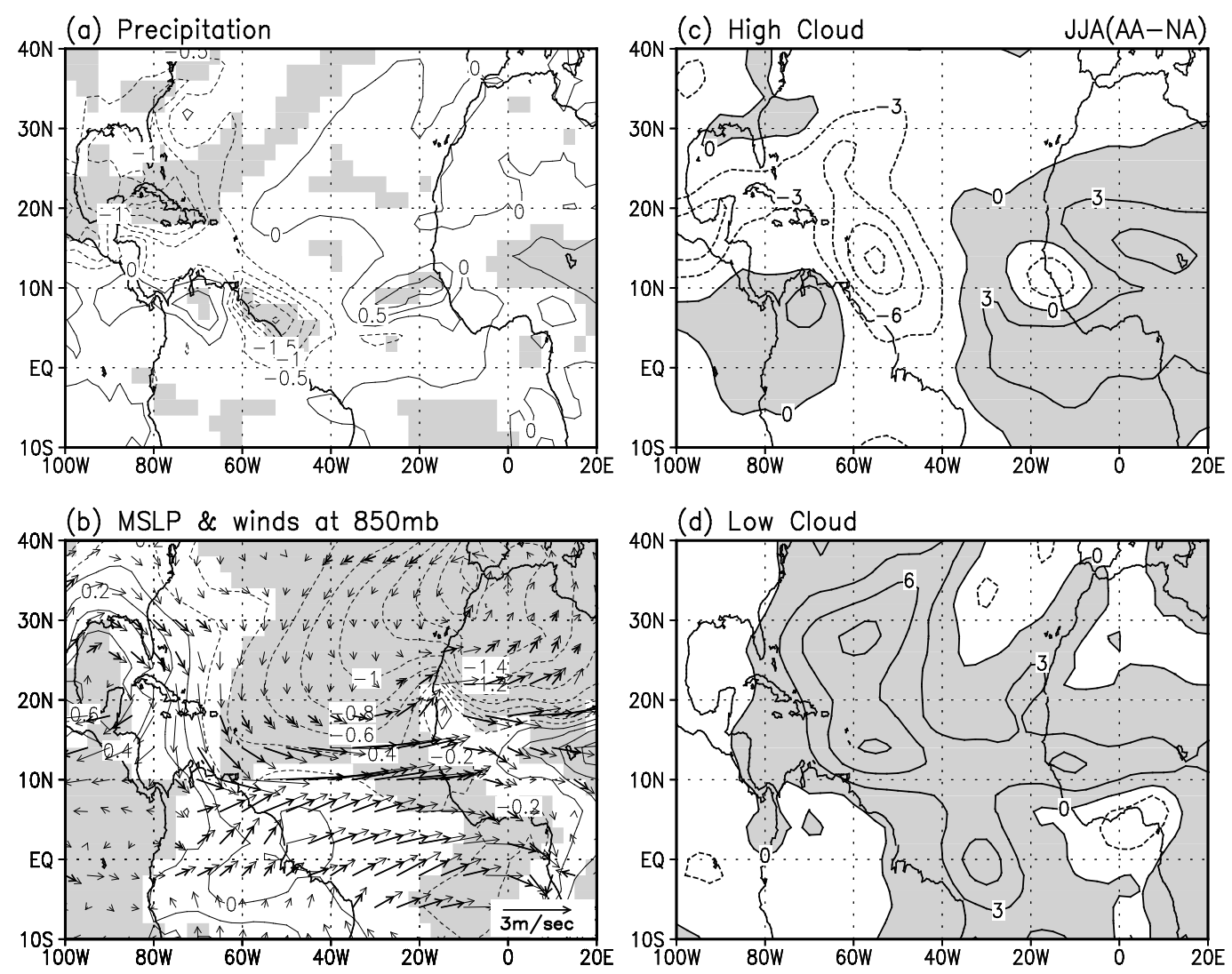

Fig. 3. JJA dust induced anomalies in (a) precipitation $\left(\mathrm{mm} \mathrm{day}^{-1}\right.$ ) and (b) $850 \mathrm{hPa}$ wind $\left(\mathrm{ms}^{-1}\right)$, and mean sea level pressure (hPa), (c) high cloud, and (d) low cloud amounts (\%). Positive (negative) anomalies are indicated by solid (dotted) contours. Anomalies in precipitation and sea level pressure exceeding 95\% statistical significance level are shaded. Wind vectors exceeding 95\% significance are bolded. Positive anomalies of cloud amounts are shaded.

between the heating within the dust layer(s) of the atmosphere and the cooling at the surface. The heating of the atmosphere (Fig. 2b) is due mostly to solar absorption by dust; accordingly the distribution of the heating mimics patterns of the dust distribution (Fig. 1c). It has large magnitudes $\left(\sim 30 \mathrm{~W} \mathrm{~m}^{-2}\right)$ near the source regions over West Africa. The surface cooling is due primarily to solar absorption by dust, and appears almost an exact replica of the atmospheric heating, with comparable magnitudes but opposite signs. The surface cooling, also referred to as the "dimming effect" (Ramanathan et al., 2005) shows marked land-sea contrast near the coast, because of the differences in the surface albedo.

Table 1 summarizes the model simulated radiation budgets, and estimates from previous studies at TOA and at the surface over the North Atlantic Ocean, separated into longwave and shortwave components. All budgets show dust aerosol shortwave forcing warms the atmosphere and cools the surface with comparable magnitudes while the longwave has the opposite effect. Overall, the net radiative effect is a warming of the atmosphere and cooling at the surface and relatively small net TOA forcing. The simulated atmospheric heating and surface cooling in our model are larger than the satellite data estimates (Zhu et al., 2007). It is also stronger than modeling results of Yoshioka et al. (2007), and the difference is understandable because the latter used higher single scattering albedo. We will discuss the sensitivity of the model results to different aerosol absorption efficiencies in Sect. 3.4. The contributions to the total surface energy fluxes from shortwave, longwave, and latent and sensible heat fluxes are discussed in Sect. 3.2.

\subsection{Anomalies in rainfall, circulation and surface fluxes}

Hereafter, we define an anomaly field as the difference in the ensemble seasonal mean between the AA and NA experiments. The rainfall difference map of AA-minus-NA (Fig. 3a) shows that Saharan dust enhances rainfall over the eastern Atlantic ITCZ and the WAM and suppresses rainfall over most of the tropical Atlantic, with the most pronounced suppression over the southern Caribbean region and Central America, reminiscent of an anomalous Walker circulation with rising motion over eastern Atlantic, and sinking motion over the western Atlantic Caribbean region (see further discussion in Sect. 3.3). The increase in precipitation 

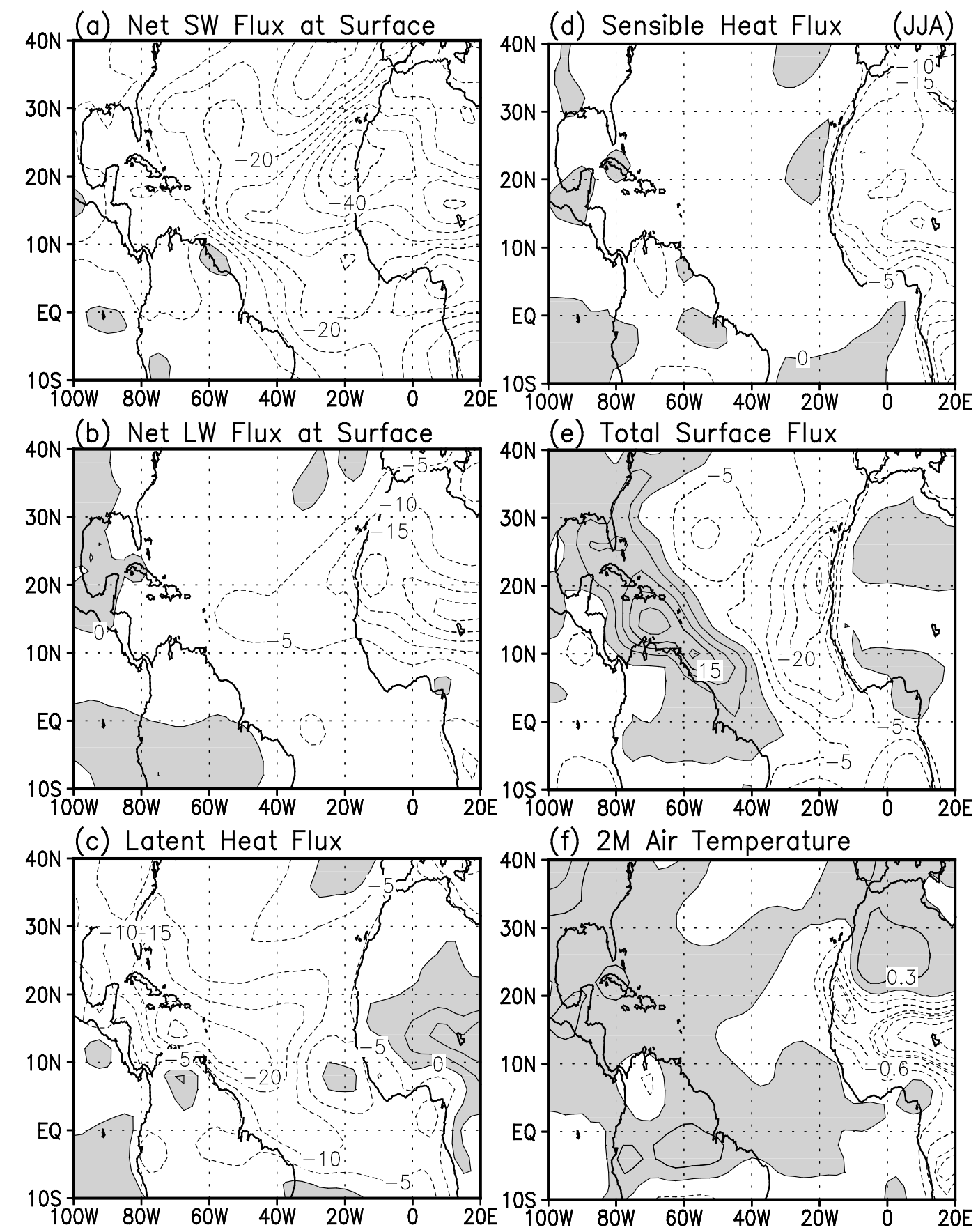

Fig. 4. JJA dust induced anomalies in (a) surface shortwave flux, (b) surface long wave flux, (c) surface latent heat flux, (d) surface sensible heat flux, (e) total surface heat flux, and (f) surface air temperature at $2 \mathrm{~m}$. All fluxes use upward-positive convention, except shortwave and total fluxes which are positive downward. Units are $\mathrm{W} \mathrm{m}^{-2}$ for fluxes and ${ }^{\circ} \mathrm{C}$ for temperature.

over the WAM land region, is statistically significant, even though much weaker, because of the model's dry bias (see Appendix for a discussion of the normalized rainfall anomaly distribution). The $850 \mathrm{mb}$ wind anomalies (Fig. 3b) suggest a large-scale Rossby wave response to increased heating over the eastern Atlantic ITCZ and reduced heating over the west- ern Atlantic, as evident in the two large-scale cyclonic circulations in the lower troposphere over the subtropical North and South Atlantic and anomalous westerly across the entire Atlantic along $5-15^{\circ} \mathrm{N}$. The mean sea level pressure pattern shows a basin-scale low over the Atlantic, coupled to high pressure ridge over the land regions of Americas, the 
tropical eastern Pacific, and the eastern WAM. The strongest westerly wind response is found over the region from equator to $15^{\circ} \mathrm{N}$ over the Atlantic and West Africa. Another region of strong wind response is an anomalous anticyclone near southeast US and the Gulf of Mexico. The circulation pattern signals a weakening, and an eastward retreat of the climatological North Atlantic High. The rainfall and wind patterns also imply anomalous rising motion over the tropical eastern Atlantic and sinking motion over the western Atlantic and Caribbean. Part of the reduced precipitation accompanied by sinking motion over the Caribbean may be related to the anomalous anticyclonic circulation which brings colder and drier air from the extratropics into the Caribbean (See further discussion in Sect. 3.3). The convergence of the northerly flow from the anticyclone, and the southerly flow from largescale cyclonic flow from the South Atlantic, gives rise to a positive rainfall anomaly over northwestern South America, limiting the westward extension of the anomalous Walker circulation. In association with the rainfall and surface pressure anomalies, high and middle cloud amounts are increased over the eastern tropical Atlantic and West Africa, and decreased over the Caribbean and the land regions of Central America. The total cloudiness pattern is similar to that shown for high clouds (Fig. 3c), and is contributed in large part by high clouds and middle clouds. In contrast, low clouds are increased over entire the tropical Atlantic $\left(10^{\circ}-30^{\circ} \mathrm{N}\right)$, the Caribbean and the northwestern Atlantic (Fig. 3d). The increased low clouds across the Atlantic in AA, is due to the presence of large-scale subsidence over the western Atlantic, and the induced cold air below the dust layer extending from the African continent. Both processes suppress deep convection. As a result, convection and clouds due to unstable marine boundary air masses, are capped at lower levels, increasing low cloud amounts (see further discussion in Sect. 3.3). As expected, changes in large-scale circulation, rainfall, and cloudiness induced by dust aerosol, lead to significant changes in surface energy balance. Figure 4a shows that the most pronounced signal at the surface is the reduction of solar radiation over the entire WACC, i.e., the solar dimming effect, as evident in the tongue of negative (positive downward) anomalies emanating from North Africa to the Atlantic, which is similar to the spatial distribution of GOCART dust AOD (Fig. 1c). Reduction in surface shortwave flux can be as large as $45 \mathrm{~W} \mathrm{~m}^{-2}$ in the tropical eastern Atlantic near the coast of West Africa. A large negative longwave flux (positive upward), indicating surface warming by the elevated dust layer, is found over West Africa land and the adjacent eastern Atlantic (Fig. 4b). Longwave radiation from ocean to atmosphere is reduced due to increased cloudiness over eastern Atlantic and the WAM region. Also countering the shortwave cooling tendency at the ocean surface, is large negative (warming effect) surface latent heat flux over most regions of the Atlantic, with maximum in the western Atlantic and the Caribbean regions (Fig. 4c). The reduction in latent heat flux over the ocean is primarily due to the decrease in total surface wind speeds, which arise because the anomalous wind opposes the climatological surface winds. Over WAM land surface, the solar dimming effect is further mitigated by a warming tendency in sensible heat as evident in a substantial reduction (positive upward) in these quantities (Fig. 4d). Over the ocean, the sensible heat flux contributions are negligible. The net effect of all the surface flux anomalies is a pronounced east-west dipole with a net excess of total energy flux $\left(10-15 \mathrm{~W} \mathrm{~m}^{-2}\right)$ in the western Atlantic and Caribbean, and a net deficit $\left(15-30 \mathrm{~W} \mathrm{~m}^{-2}\right)$ in the eastern tropical Atlantic (Fig. 4e). Over the land region, the net surface energy is nearly in balance, because the land surface equilibrates rather quickly with the surface fluxes. The east-west surface flux contrast over the ocean is evident in the differences of cooling of surface air over the WAM land and adjacent eastern Atlantic, and a widespread warming of SST and surface air over the western Atlantic and Caribbean (see Fig. 4f for surface air temperature). The cooling of the ocean and the land in the east is due mainly to the dimming effect by Saharan dust, while the heating of the ocean to the west results from a reduction of surface latent heat flux. The net effect of the surface warming and cooling is to provide a damping effect on the atmospheric feedback processes, discussed in the next section.

\subsection{The Elevated Heat Pump (EHP) mechanism}

We further elucidate the physical mechanisms that underpin the model responses of WAAC atmospheric water cycle to the prescribed aerosol forcing. Figure 5a-c show the longitude-height cross-sections of GOCART dust loading, zonal wind, rainfall, circulation and potential temperature anomalies along $5-15^{\circ} \mathrm{N}$, which lies along the path of the maximum dust loading. As evident in Fig. 5a, the dust layer is thick and extensive, with substantial concentration up to $500 \mathrm{hPa}$ over the African continent, and a thick canopy that extends across the entire Atlantic Ocean. The dust layer thickness tapers off away from the continent due to the deposition processes. The anomalous westerly flow is closely tied to the shape of the dust layer, rising as it approaches the continent, with the maximum westerlies located off the coast of West Africa near $40-30^{\circ} \mathrm{W}$ and capped under the warm dust canopy. Above the dust layer, the anomalous flow is largely easterly. The anomalous low-level westerlies increase moisture transport from the central and eastern Atlantic and produce rainfall over the oceanic region off West Africa and further inland, while suppressing rainfall over the central Atlantic and WAAC (Fig. 5b). The east-west circulation and potential temperature anomalies are shown in Fig. 5c. At the upper part of the dust layer, the shortwave heating is larger than the longwave cooling, resulting in net heating there. Beneath the dust layer, longwave outweighs shortwave forcing, producing overall cooling. Over land, the dust radiative forcing from reduced shortwave is larger than that of increased longwave, causing the surface 

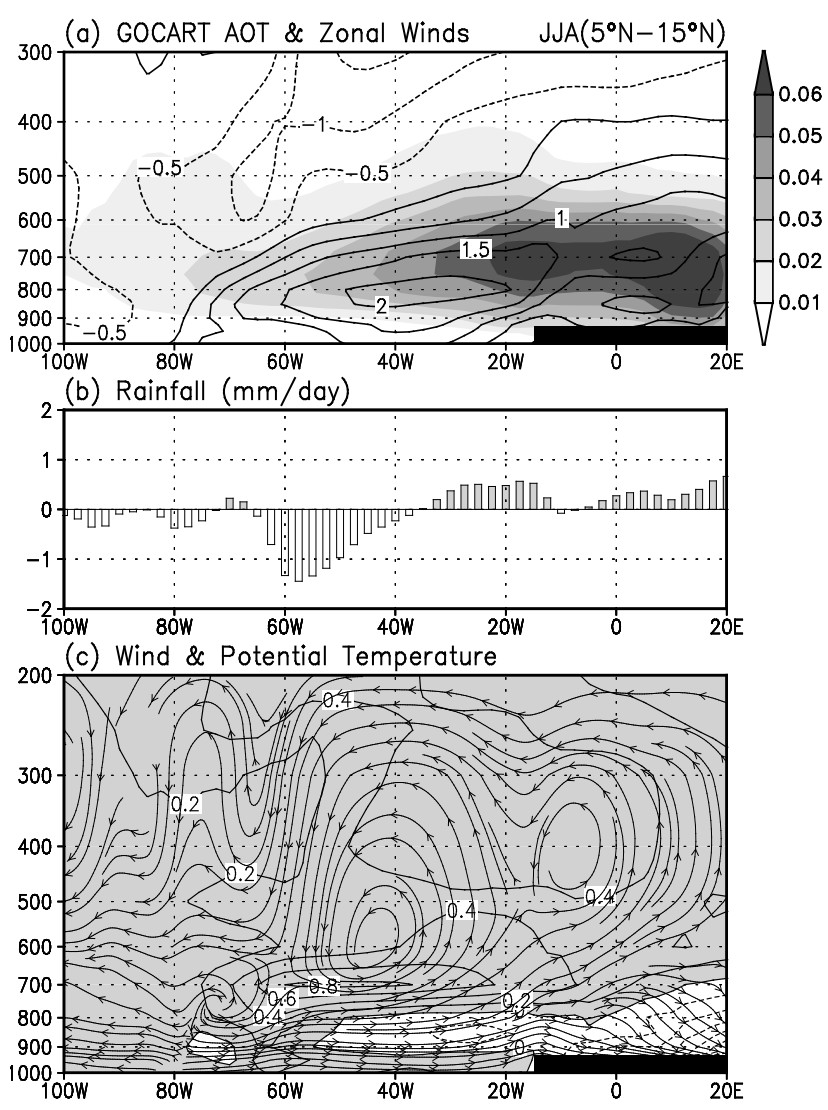

Fig. 5. East-west cross-section across the WAAC region of dust induced anomalies in JJA, for (a) zonal wind (contour in $\mathrm{ms}^{-1}$ ) and GOCART aerosol optical thickness (shading, non-dimensional unit), (b) rainfall anomaly (mm day ${ }^{-1}$ ) and (c) zonal and vertical wind streamline and potential temperature (contour in ${ }^{\circ} \mathrm{C}$ ).

to cool, and atmospheric boundary layer mixing extends the cooling to the lower troposphere. This produces a cold air dome over the deserts, which extends from the WAM land region to the central Atlantic $\left[50^{\circ} \mathrm{W}\right]$. As a result of water cycle/condensation heating feedback, the entire troposphere gets relatively warmer, except near the surface and beneath the dust layer. Maximum heating is found in the upper part of the dust layer $(800-600 \mathrm{hPa})$ near [50 W-30 W]. This coupled with the cold tongue extending from the West African land, creates a characteristic stable (warm above and cold below) dipole temperature anomaly in the lower troposphere over the eastern Atlantic ocean. This stable layer caps convection from the unstable marine boundary layer below, thereby increasing low level clouds. The anomalous largescale circulation features a large-scale east-west overturning cell, with general rising motion over the eastern Atlantic and West Africa and sinking motion over the western Atlantic and the Caribbean, is analogous to a Walker-type Circulation. A distinctive feature of this anomalous circulation is that as the low-level westerlies approach the West Africa land, it bifurcates into two branches. One branch sinks into the cold dome, as the air there is cooler and exerts negative buoyancy, relative to the environment. A second branch glides above the cold dome, by-passing the stable environment beneath, and joins the rising motion above it, as a part of the large-scale east-west circulation. This branch brings in warm, moist (high potential temperature) air from the central and eastern Atlantic to the coastal and inland regions of the WAM, fueling the enhanced precipitation there (Fig. $5 \mathrm{~b}$ and c). The enhanced rainfall tend to be most pronounced near the coast around $20^{\circ} \mathrm{W}$, and further inland $\left[15^{\circ} \mathrm{E}-20^{\circ} \mathrm{E}\right]$, with a minimum near $10^{\circ} \mathrm{W}$. The rainfall maxima coincide well with the two centers of rising motion (Fig. 5c). The coastal maximum is primarily driven by condensation heating from convection associated with the moist marine air of the eastern Atlantic, and the inland maximum by both dust radiative heating and by convection, which arises from the upper part of the dust layer, and depends on long-distance transport of moisture further inland (see further discussion in Fig. 6).

The structures of the heating and cooling components are shown as vertical cross-sections across Atlantic basin along $5-15^{\circ} \mathrm{N}$ (Fig. 6). The shortwave heating pattern (Fig. 6a) reveals the large-scale footprint of the Saharan dust distribution, showing the elevated heating by dust lofted to the midtroposphere over the Sahara, and the dust plume extending into western Atlantic and Caribbean. The pronounced longwave heating near the surface and cooling above, over the central and eastern Atlantic $\left(60-20^{\circ} \mathrm{W}\right)$, is due to the formation of low clouds. The largest longwave warming is found in the upper troposphere near $300 \mathrm{hPa}\left[60-80^{\circ} \mathrm{W}\right]$ where the strong longwave cooling by clouds would have occurred in the absence of aerosol forcing. The induced condensation heating pattern (Fig. 6b) is consistent with the anomalous east-west circulation associated with a stronger WAM, with heating (rising motion) over the eastern Atlantic ITCZ, and cooling (sinking motion) over the Caribbean. The large suppression in condensation heating over the Caribbean may also stem from the anomalous anticyclone over the Gulf of Mexico, which forms as the climatological North Atlantic High weakens by the dust heating. The anticyclone causes sinking and warming of the air by adiabatic compression, and brings in drier air from the extratropics, further suppressing convection over the Caribbean. The effect of atmospheric turbulent mixing is generally small in the free troposphere, but large over the land surface, and the marine boundary layer (Fig. 6d). This is consistent with the pronounced negative anomaly over WAM land surface [20 W-20 E], where turbulent mixing in the atmospheric boundary layer is responsible for maintaining equilibrium with the cooler land surface, and the formation of the cold air dome. Comparing the total radiative heating (Fig. 6e) to the shortwave and longwave respectively indicates that that shortwave heating, which is the main dust forcing from solar absorption, is more dominant in the eastern part of the domain, especially over the WAM land region, while the longwave effect, which are 

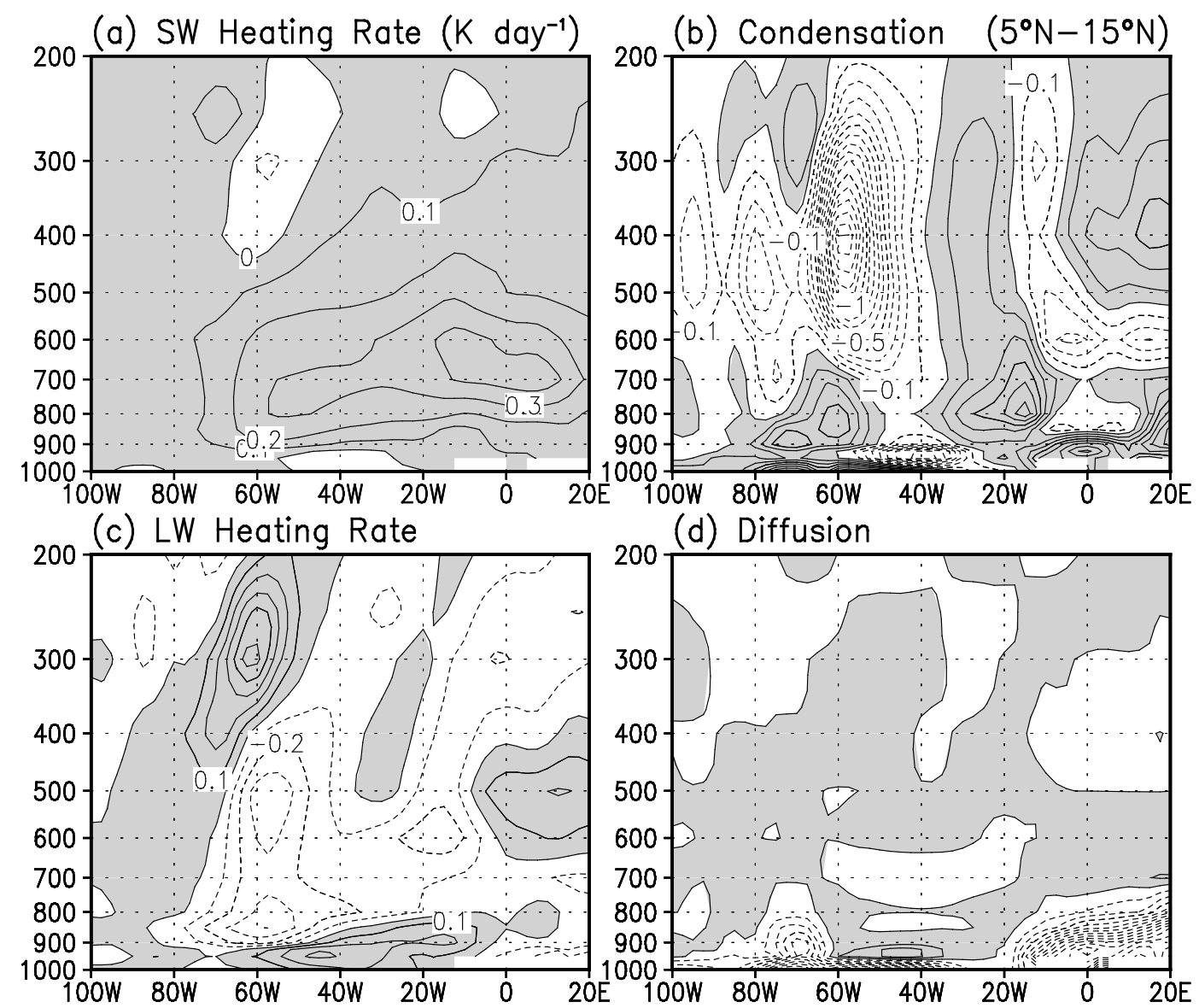

(d) Diffusion
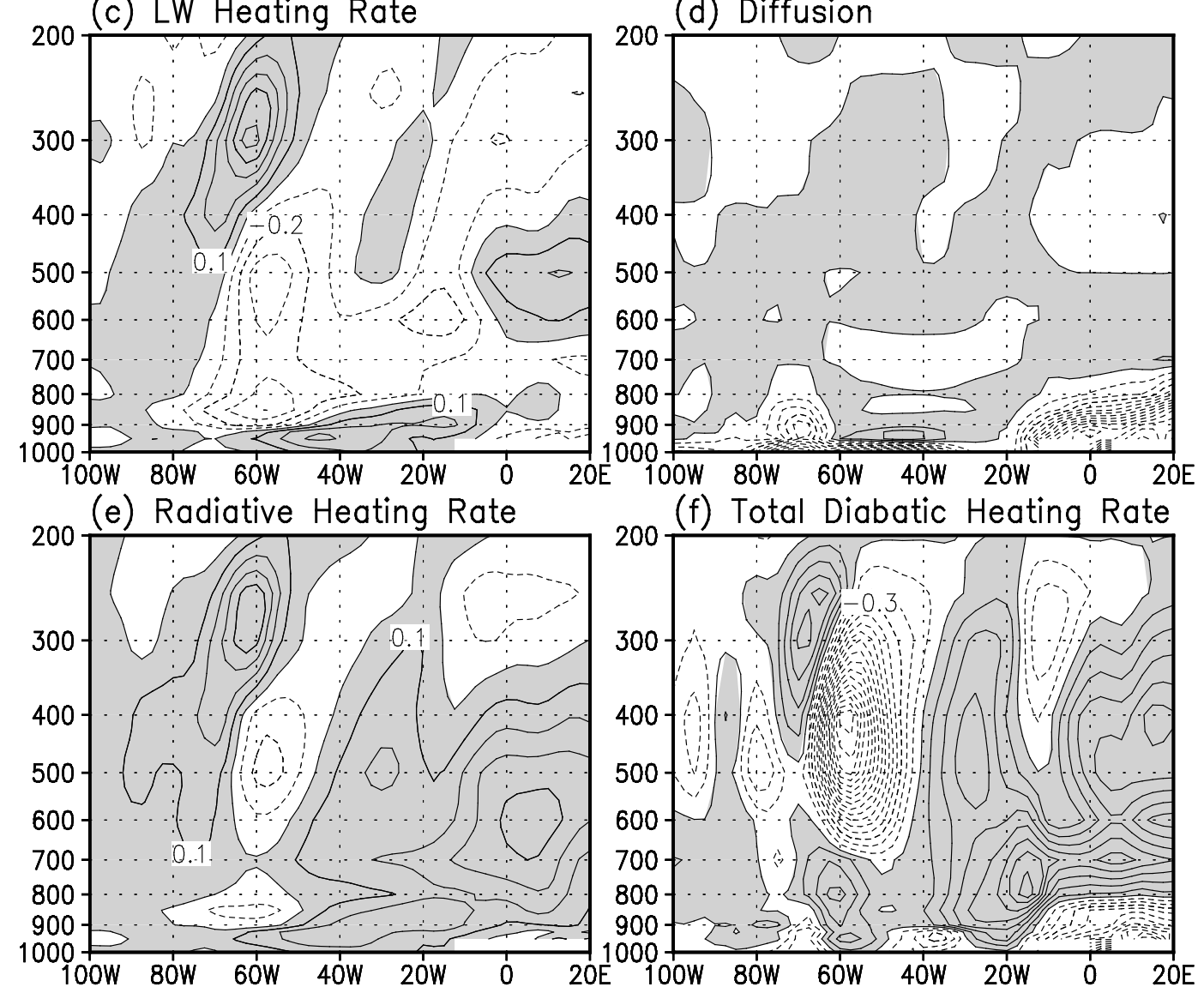

Fig. 6. Vertical zonal cross-section of heating rates for (a) shortwave, (b) longwave, (c) condensation, and (d) diffusion. Units of heating rate is in ${ }^{\circ} \mathrm{C}$ per day.

due mostly to induced cloud changes are more prominent in the western part. Figure 6f shows the distribution of the total heating which includes all the heating terms combined. To a first approximation, the total heating is balanced by the adiabatic cooling (heating) by the rising (sinking) air in the large-scale circulation. The similarity between the total heating, and the latent heating alone (Fig. 6b) further evinces the importance of latent heating in maintaining the anomalous Walker circulation, implying rising air in the upper part of dust layer and air above, in the eastern part of the domain. The implied sinking motion in the lower troposphere and near the surface is a result of strong cooling of the land surface of West Africa due to solar dimming effect, mixed throughout the atmospheric boundary layer by 
(a) GOCART AOT \& Zonal Winds JJA $\left(10^{\circ} \mathrm{W}-10^{\circ} \mathrm{E}\right)$
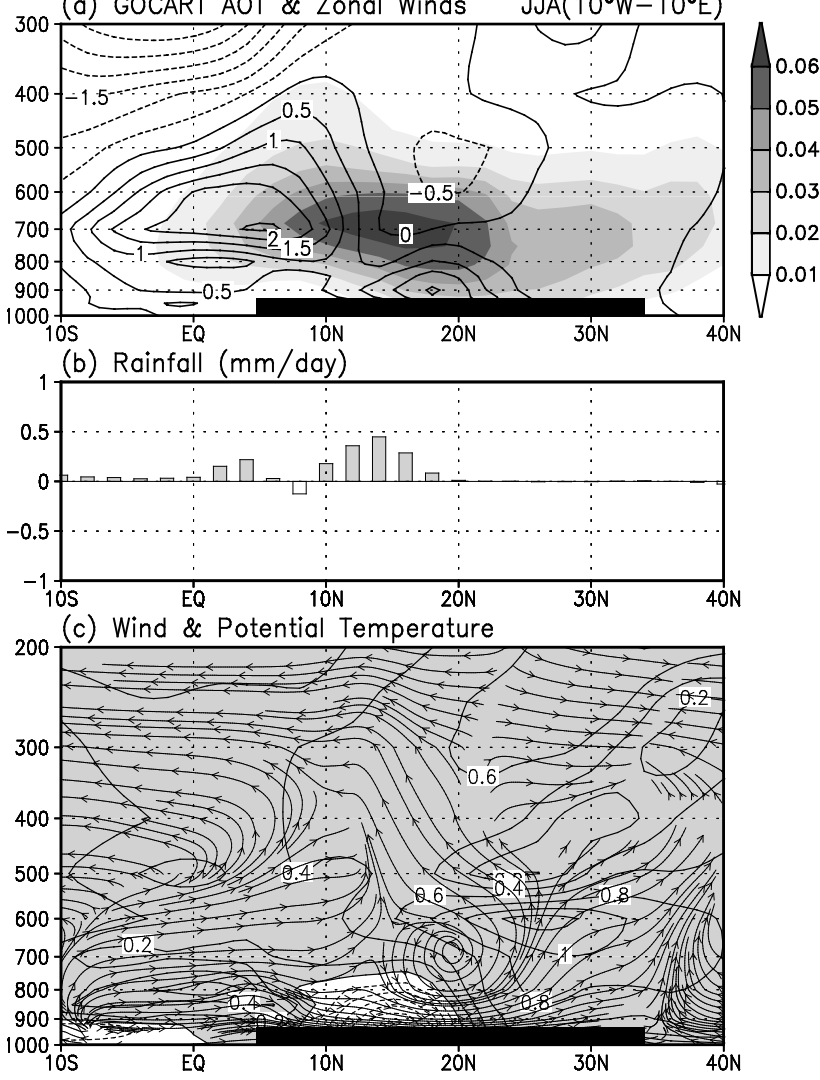

Fig. 7. Vertical meridional cross-sections averaged over the West Africa/eastern tropical Atlantic region $\left(10^{\circ} \mathrm{W}-10^{\circ} \mathrm{E}\right)$ of JJA dust induced anomalies in (a) zonal wind (contour in $\mathrm{ms}^{-1}$ ) and GOCART aerosol optical thickness (shading, non-dimensional unit), (b) rainfall anomaly $\left(\mathrm{mm} \mathrm{day}^{-1}\right)$ and (c) meridional and vertical wind streamline and potential temperature (contour in ${ }^{\circ} \mathrm{C}$ ).

diffusive processes. The positive total heating in the lower troposphere is consistent with rising motion associated with a moist unstable boundary, and increased low clouds, capped by an inversion, and large scale subsidence. The two total diabatic heating centers, one over the coastal region near $20 \mathrm{~W}$, and another near $15 \mathrm{E}-20 \mathrm{E}$ coincide the two rainfall maxima noted earlier. Comparing the total radiative and condensation heating terms, it can be inferred that the coastal rainfall maximum is due mainly to condensation heating, while the inland maxium is due both to condensation as well as dust radiative heating.

In addition to the east-west circulation anomalies, the dust heating induces similar albeit weaker circulation and temperature anomalies associated with a northward shift of the east Atlantic ITCZ and the WAM rain belt. Figure 7 shows the meridional cross-sections of dust, wind, rainfall and temperature fields over the West Africa land region, $10^{\circ} \mathrm{W}-10^{\circ} \mathrm{E}$. Here, the highest dust concentration is found at $700 \mathrm{hPa}$ at $15^{\circ} \mathrm{N}$ (Fig. 7a). The anomalous zonal flow features a lower troposphere westerly jet at $700 \mathrm{hPa}$, between $5-10^{\circ} \mathrm{N}$ near the southern edge of the dust zone immediately to the north of the Gulf of Guinea, and a weaker near-surface westerly jet at the lower portion of the dust layer over the Sahara desert near $20^{\circ} \mathrm{N}$. At the center of the dust layer, the anomalous flow is weakly easterly. Altogether, the zonal wind anomalies have the effects of concentrating and shifting the climatological lower troposphere easterly jet slightly northward, and drawing the monsoon low level westerlies northward to the southern edge of the dust layer as well as producing a near-surface westerly jet beneath the thickest dust layer over the desert (see Fig. 7a). These zonal wind structures are consistent with those shown in Fig. 5. Associated with the wind changes is increased rainfall over the WAM land region $\left(10^{\circ}\right.$ $20^{\circ} \mathrm{N}$ ), but there is a little change to the south (Fig. 7b). Both the wind and rainfall patterns signify a strengthening of the WAM. The overall meridional Hadley-type circulation and temperature anomalies are shown in Fig. 7c. The heating of the atmosphere is evident in the positive temperature anomaly covering nearly the entire troposphere, except for the cold dome over the WAM land region $\left[10-20^{\circ} \mathrm{N}\right]$. As in the case of the anomalous Walker circulation, warm and moist air is drawn in at low levels by the meridional wind from the Gulf of Guinea to the WAM land region, arising above the cold dome over land, and shifting the rainfall to the north. Here, the rising and sinking branches of the largescale meridional circulation are not as robust as its east-west counterpart; nevertheless, it is accompanied by low-level recirculations over the desert and between the Gulf of Guinea $\left(0-5^{\circ} \mathrm{N}\right)$, and the land region to the north. The partition of the heating terms shows that over land while the direct shortwave heating due to dust (Fig. 8a) is opposed by the longwave radiation cooling below the dust layer (Fig. 8c), the net radiative effect including both aerosol and clouds are to warm the entire lower and middle troposphere over the WAM land region (Fig. 8e). The condensation heating in the middle and upper troposphere near $15^{\circ} \mathrm{N}$ (Fig. 8b) is associated with deep convection generated by positive feedback from the induced circulation, while the lower level condensation heating is due to warm rain associated with the low level recirculations, and the advection of relative warm and moist air from the Gulf of Guinea into the cold dome over the WAM land region. The large diffusive cooling is due to the surface cooling by the dimming effect, and by strong mixing in the atmospheric boundary over WAM land and the Gulf of Guinea. Overall, the total heating (Fig. 8f) features an elevated heat source from the upper part of the dust layer to the free troposphere up to about $300 \mathrm{hPa}$, and a heat sink from the surface to the lower part of the dust layer. Similar to the anomalous Walker circulation, the EHP feedback mechanism overcomes the low level stability induced by the dimming effect at the surface, and forces an anomalous meridional cell with rising motion over the dust layer over land, and sinking motion over ocean to the south, effectively shifting the WAM rainbelt northward. 

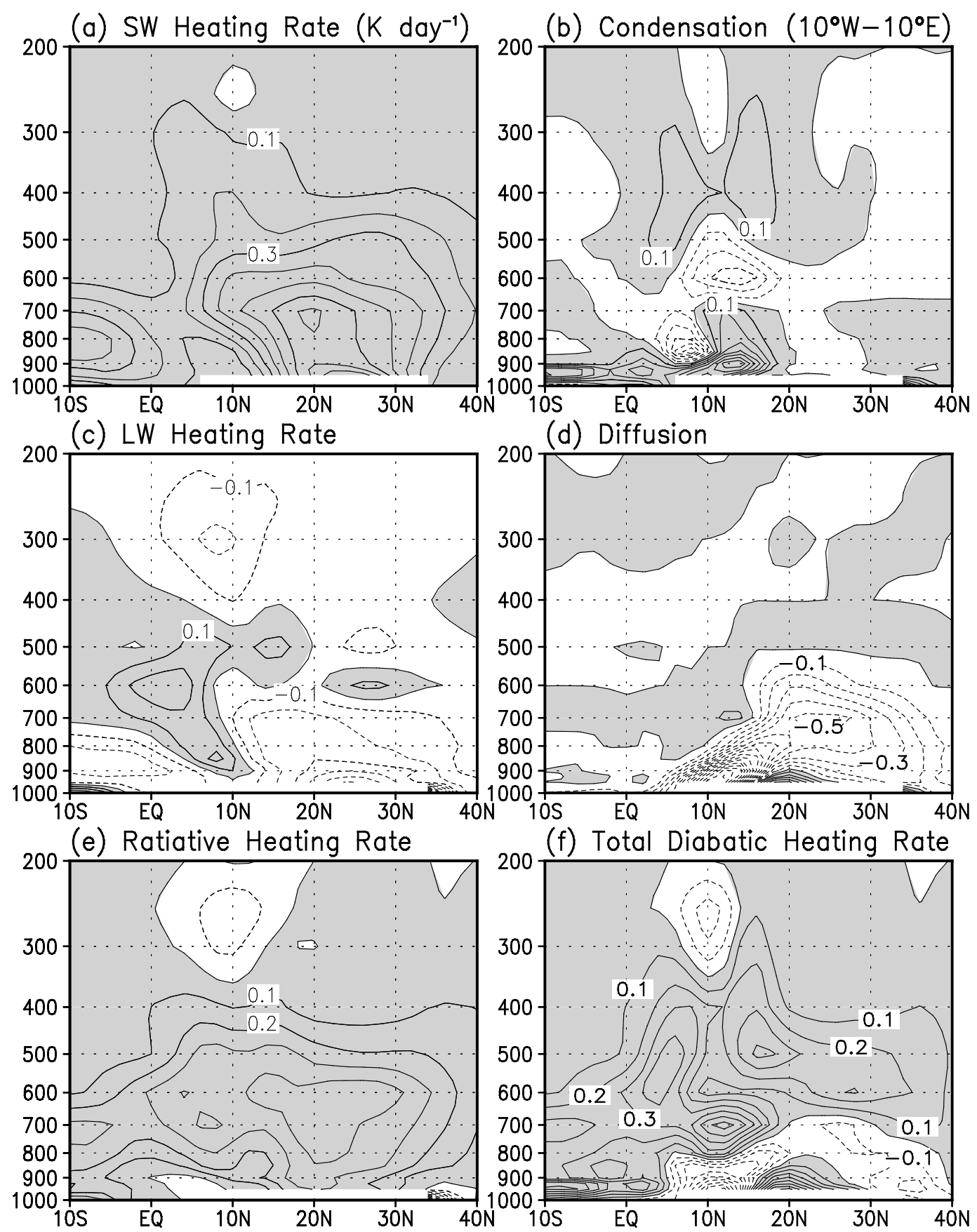

Fig. 8. Vertical meridional cross-section of heating rates for (a) shortwave, (b) longwave, (c) condensation, and (d) diffusion. Heating rate is in unit of ${ }^{\circ} \mathrm{C}$ per day.

\subsection{Sensitivity to dust single scattering albedo}

As shown from previous studies (Sokolik and Golistsyn, 1993; Miller et al., 2004, and others), there are large uncertainties regarding the magnitude of the radiative forcing of Saharan dust; it depends on the dust loading, and optical properties of dust aerosols, which are strong functions of the physical and chemical properties of the dust, e.g., the pro- portion of silt to clay, size distribution, iron oxide hematite content, and degree of mixing with other aerosol species being transported away from the source region. The absorption of solar radiation increases for dust with high iron oxide hematite (Chester and Johnson, 1971; Voltz, 1973), and for large dust particles, that are externally mixed with black carbon aerosols from biomass burning (Zhu et al., 2007). A low $\omega_{o}(<0.95)$ is appropriate for these types of dust aerosols. On 


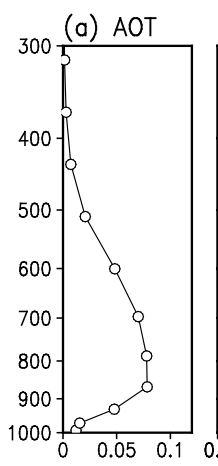

(b) Dust Radiative Heating Rate [K/day]
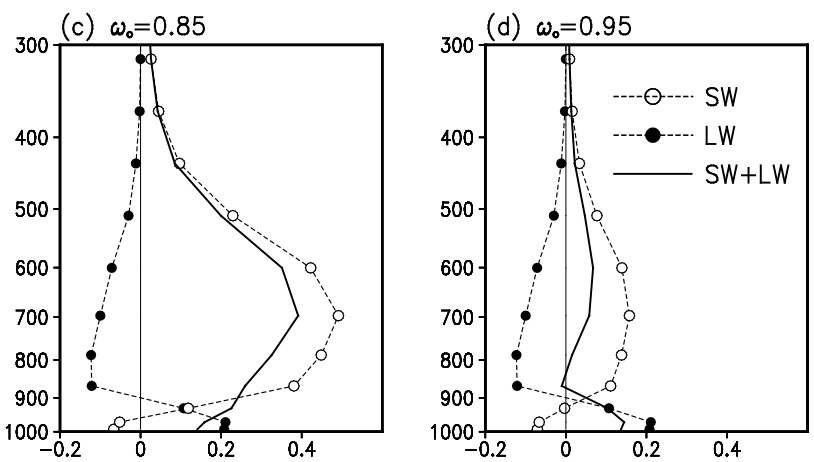

Fig. 9. Vertical profile of (a) Saharan dust layer off coast of W. Africa from GOCART, (b) dust radiative heating as a function of single scattering albedo, $\omega_{o}$ for the same dust profile with $\mathrm{AOD}=0.35$, (c) atmospheric heating due to SW and LW, and $\mathrm{SW}+\mathrm{LW}$ for $\omega_{o}=0.85$, and (d) atmospheric heating due to $\mathrm{SW}$ and $\mathrm{LW}$, and $\mathrm{SW}+\mathrm{LW}$ for $\omega_{o}=0.95$.

the other hand, a high $\omega_{o}(>0.95)$ is representative of smaller size dust particle with high clay contents. Recent AERONET (Version-2) improved retrieval algorithm, which takes into account the bidirectional reflectance of background radiation as a function of zenith angle has estimated significantly lower $\omega_{0}$ for dust at visible and ultraviolet wavelengths as compared to earlier satellite retrievals (Eck et al., 2008). Recently, results from the NASA AMMA field campaign has also found moderate-to-high absorbing range of $\omega_{o}$, $0.9 \pm 0.05$ and $0.96 \pm 0.01$ for Saharan dust off the coast of Africa (Jeong et al., 2008).

While the absorptivity of Saharan dust is still a subject of extensive data analysis and active debate among the radiation community, we venture to provide an estimate of the sensitivity of the model response to the dust aerosol absorptivity. For this purpose, we calculated the clear-sky radiative forcing based on single-column version of the model, to the full range of possible values of SSA, $\omega_{o}$, at $0.55 \mu \mathrm{m}$ for Saharan dust from $\omega_{0}=0.7$ (highly absorbing) to unity (non-absorbing). Our calculations are based on a typical GOCART dust profile off the coast of Africa during July, the peak dust season, characterized by high AOD $(=0.35)$, with the dust layer between 950-600 hPa (Fig. 9a). Clearly, the vertical extent and magnitude of net atmospheric heating varies in proportion to the absorptivity of dust (Fig. 9b). For strongly absorbing dust $\left(\omega_{0}<0.85\right)$, the heating rate can be greater than $0.5 \mathrm{~K} \mathrm{day}^{-1}$ in the $750-600 \mathrm{hPa}$ layer. For weakly absorbing dust $\left(\omega_{o}>0.95\right)$, the net heating is less than $0.1 \mathrm{~K} \mathrm{day}^{-1}$, or even negative, with weak warming below $950 \mathrm{hPa}$. The shortwave and longwave contributions to the heating profile for $\omega_{o}=0.85$, is shown in Fig. 9c. For strongly absorbing dust, the net heating within the upper part of the dust layer $(900-600 \mathrm{hPa})$ is primarily due to the shortwave absorption, which exceeds the longwave cooling. The magnitude of the net heating in the dust layer is of the order of $0.2-0.35 \mathrm{~K} \mathrm{day}^{-1}$, which is at the higher end of the estimated range by Zhu et al. (2007) estimates. This may be due to the higher dust AOD, the lower $\omega_{o}$, and the more elevated dust profile in our model. From the surface to the base of the dust layer, the net heating is a result of warming by downwelling longwave, which outweighs cooling due to shortwave attenuation. Based on one-dimensional radiative transfer calculations without feedback, warming of the dust layer aloft, and cooling at the surface would increase the dry static stability of the lower troposphere, and inhibit convection. However, in our simulations, the initial atmospheric heating by dust is sufficiently strong to initiate the EHP mechanism to overcome the stability effect of dust-radiation interaction. In contrast, for weakly absorbing dust $\left(\omega_{0}>0.95\right)$, the longwave cooling effect becomes increasing important. At $\omega_{o}=0.95$ the shortwave heating in the dust layer is only slightly larger than the longwave cooling (Fig. 9d). The resulting net heating $\left(<0.1 \mathrm{~K} \mathrm{day}^{-1}\right)$ in the elevated dust layer is too weak to excite discernable EHP responses. Note that the solar absorption by aerosol is proportional to the co-albedo $=1-\omega_{o}$, Thus as $\omega_{o}$ is changed from 0.85 to 0.95 , solar absorption is reduced by a factor of three. Analyses of additional GCM sensitivity simulations using different values of $\omega_{o}$ have confirmed that the EHP mechanisms are effective only for absorbing dust $\omega_{0}<0.95$ (not shown). This result is in agreement with Solmon et al. (2008).

\section{Conclusions}

Using the NASA coupled atmosphere with a new MLO model, we have identified a basic "elevated heat pump" (EHP) feedback mechanism, initiated by radiative effect of absorbing Saharan dust in the atmosphere, which can play a role in the altering the water cycle and climate states of West Africa and the tropical Atlantic (Fig. 10). Our results suggest the following scenario associated with the EHP mechanism. During the boreal summer season, dust and hot air rises to high altitude over the heated Saharan desert, and transported across the Atlantic to the Caribbean region. The Saharan dust absorbs solar radiation and warms the atmosphere by absorbing solar radiation, as well as cools the earth surface by reducing the solar radiation reaching the surface. On the other 


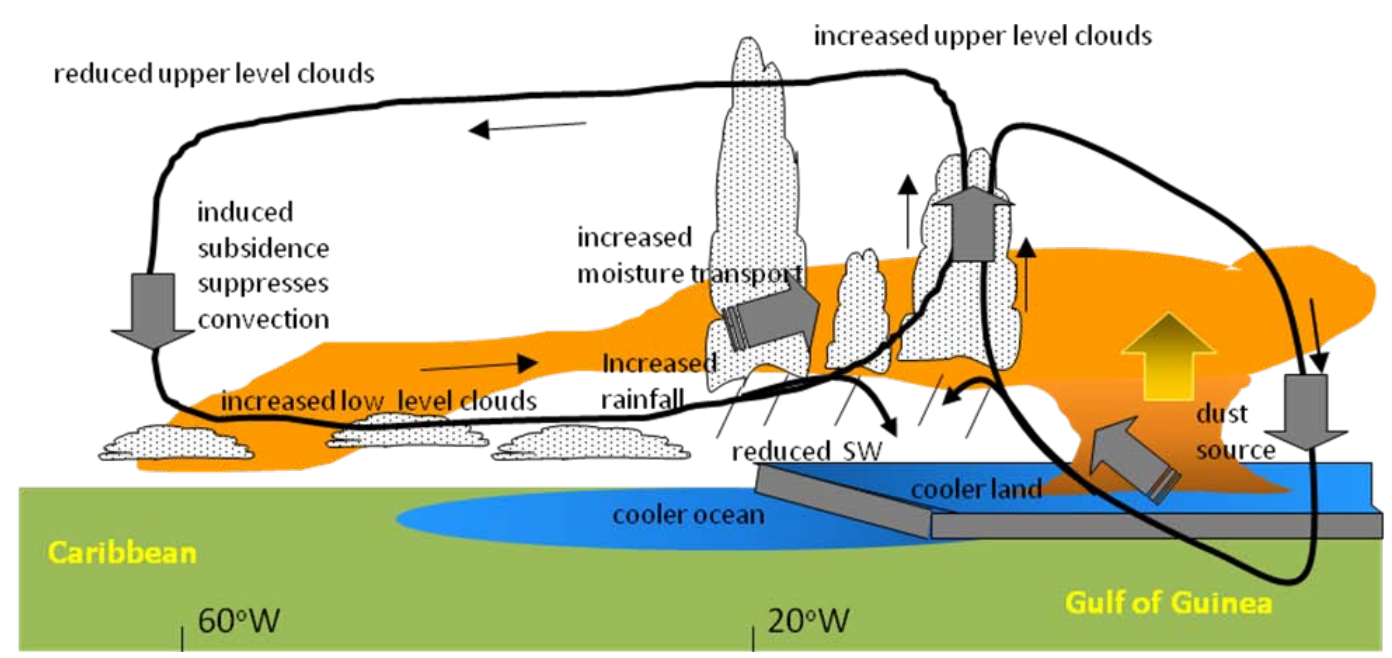

Fig. 10. Schematic diagram showing Saharan dust induced anomalous Walker-type and Hadley-type circulations, and accompanying changes in components of the atmospheric water and energy cycle, across West Africa, the Atlantic and the Caribbean.

hand, longwave emission by dust cools the atmosphere and warms the surface. Because of the longwave mitigation, the total net radiation forcing at the top of the atmosphere over the North Atlantic is relative small compared to that of the atmosphere, and/or the surface. For moderate-to-strong absorbing dust, shortwave radiative forcing by dust outweighs the longwave cooling effect. This leads to anomalous cooling over the WAM land surface, and the troposphere below the dust layer. Together, they increase the static stability of the atmosphere and that inhibits moist convection. Moreover, absorption of shortwave radiation in the elevated dust layer exceeds the longwave cooling, resulting in net warming of the lower to middle troposphere. As the warmed air rises, it draws in low-level air, which reinforces the seasonal influx of moist air from the eastern Atlantic and the Gulf of Guinea into Sahel region. The incoming moist air rides over the cooler air mass near the surface, that enhances rainfall in the eastern Atlantic ITCZ off the coast of West Africa, and shift rainfall northward over the WAM land region. The anomalous condensation heating warms the middle and upper troposphere and drives a large-scale Rossby wave response, with anomalous low-level cyclonic circulation over the North and South subtropical Atlantic, and anticyclonic circulation over the Gulf of Mexico, and the southeastern US. The above circulation feature is manifested in an anomalous large-scale Walker-type overturning cell producing rising motion over the eastern Atlantic/West Africa and sinking motion over the western Atlantic and Caribbean region. Also generated by the dust heating is an anomalous meridional Hadley-type overturning cell, with embedding shallow re-circulation, which transports moisture from the Gulf of Guinea to the land region of West Africa, enhancing monsoon rain over land, and strengthening the WAM. The present results are consistent with previous studies (Lau and Kim, 2007a, b) which suggested an anomalous Walker-type circulation over the Atlantic, with subsidence motion over the Western Atlantic and cooling of the North Atlantic by Saharan dust may suppress hurricane activity.

We also find that surface energy balance of the Atlantic and West Africa is substantially altered as a result of the dust induced water-cycle feedback. The land and oceanic surfaces underneath the dust canopy are cooled because absorption and backscattering by dust aerosols reduce the solar radiation reaching the surface. Over the West Africa monsoon land and the eastern Atlantic ITCZ, the cooling is reinforced by the increased convective clouds producing thick anvils, induced by the atmospheric feedback. In the western Atlantic/Caribbean, the model shows net surface warming, due to reduced evaporation over the ocean, caused by a reduction in total surface wind speed by the anomalous circulation. Sensible heat flux is strongly reduced over the land surface because of the reduction in land-surface temperature, but has little impact over the ocean. The net result is an east-west differential surface fluxes which leads to anomalous cooling in the eastern Atlantic and warming in the western Atlantic and Gulf of Mexico. The interactive SST and land surface provide damping effects on the atmospheric feedback.

Finally, we stress that this work represent the first step in attempting to understand the very complex responses of the regional water cycle in the WAAC, and interact with local meteorology, to aerosol forcing. Clearly, the results will strongly influence by the seasonal distribution of different species of aerosols, particularly the proportion of absorbing vs. non-absorbing aerosols. Here we only focus on effects of absorbing aerosols, mainly dust, which are dominant over the north Atlantic in June-August. Our results show that the EHP effects are minimized for reflective dust with SSA $>0.95$. However it is possible that including the 


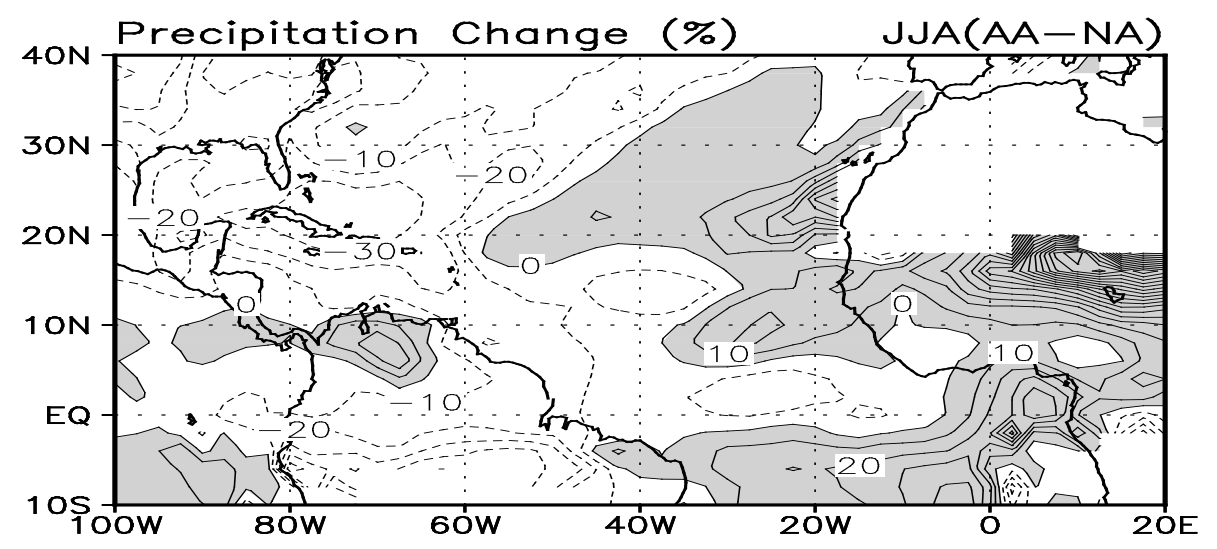

Fig. A1. Spatial pattern of percentage change of rainfall anomaly (AA-minus-NA), induced by the EHP mechanism.

microphysical effect of aerosols may cause invigoration of convection in a moist environment by inducing ice nucleation, even with reflecting dust. Furthermore, aerosol induced responses may be confounded by climate-scale forcing such as intraseasonal oscillations, El Nino, and decadal scale variations of SST and land surface conditions. These issues will be addressed in future work.

\section{Appendix A}

As stated in the main text, the fvGCM tend to have a dry bias over the African land, the Sahel and the inland region of the WAM. This may explain the relative weak rainfall signal over these regions shown in Fig. 3a. To normalize the rainfall changes, we show the percentage increase in rainfall (AA-minus-NA) relative to the model climatology (Fig. A1). Areas with climatological rainfall less than $0.05 \mathrm{~mm} /$ day are not shown. Here, it can be seen that the positive rainfall over the eastern Atlantic anomalies extend further inland over the WAM region, with a largest percentage increase (20-100). About 10 to $20 \%$ increase of rainfall is found in the eastern half of ITCZ and northern Brazil. Rainfall suppression over Caribbean region is more than $30 \%$. In this picture the EHP impact in enhancing rainfall in eastern portion of the domain, and reducing rainfall in the western portion is quite clear. This anomalous rainfall distribution generally shows opposite pattern to the model bias discussed in Fig. 1, i.e. positive anomalies over dry bias region and negative bias over wet bias region. Hence, the aerosol radiative forcing reduced model bias.

Acknowledgements. This work is supported jointly by the Precipitation Measuring Mission, the NASA AMMA program, and the program on Interdisciplinary Investigation, NASA Headquarters, Earth Science Division. Computational resources supporting this work were provided by the NASA High-End Computing (HEC) Program through the NASA Center for Computational Sciences (NCCS) at the Goddard Space Flight Center.
Topical Editor F. D'Andrea thanks three anonymous referees for their help in evaluating this paper.

\section{References}

Chester, R. and Johnson, L. R.: Trace element geochemistry of North Atlantic Aeolian dusts, Nature, 231, 176-178, 1971.

Chin, Mian, Diehl, T., Ginoux, P., and Malm, W.: Intercontinental transport of pollution and dust aerosols: implications for regional air quality, Atmos. Chem. Phys., 7, 5501-5517, 2007, http://www.atmos-chem-phys.net/7/5501/2007/.

Chin, M., Ginoux, P., Kinne, S., Torres, O., Holben, B. N., Duncan, B. N., Martin, R. V., Logan, J. A., Higurashi, A., and Nakajima, T.: Tropospheric Aerosol Optical Thickness from the GOCART Model and Comparisons with Satellite and Sun Photometer Measurements, J. Atmos. Sci., 59, 461-483, 2002.

Chin, M., Chu, D. A., Levy, R., Remer, L., Kaufman, Y., Holben, B. N., Eck, T., Ginoux, P., and Gao, Q.: Aerosol distribution in the Northern Hemisphere during ACE-Asia: Results from global model, satellite observations, and Sun photometer measurements, J. Geophys. Res., 109(D23), D23S90, doi:10.1029/2004GL02014, 2004.

Chou, M.-D. and Suarez, M. J.: An efficient thermal infrared radiation parameterization for use in general circulation models. NASA Tech. Memo. 104606, vol. 3, 85 pp., NTIS N95-15745, 1994.

Chou, M. D. and Suarez, M. J.: A Solar Radiation Parameterization for Atmospheric Studies, NASA NASA Tech. Memo. 104606, vol. 15, 38 pp, 1999.

Dai, Y., Zeng, X., Dickinson, R. E., Baker, I., Bonan, G., Bosilovich, M., Denning, S., Dirmeyer, P., Houser, P., Niu, G., Oleson, K., Schlosser, A., and Yang, Z.-L.: The Common Land Model (CLM), B. Am. Meteorol. Soc., 84, 1013-1023, 2002.

de Boyer Monte'gut, C., Madec, G., Fischer, A. S., Lazar, A., and Iudicone, D.: Mixed layer depth over the global ocean: An examination of profile data and a profile-based climatology, J. Geophys. Res., 109, C12003, doi:10.1029/2004JC002378, 2004.

Eck, T. F., Holben, B. N., Reid, J. S., et al.: Spatial and temporal variability of column integrated aerosol optical properties in the southern Arabian Gulf and United Arab Emirates in summer, J. Geophys. Res., 113, D01204, doi:10.1029/2007JD008944, 2008. 
Ginoux, P., Chin, M., Tegan, I., Prospero, J., Holben, B. N., Dubovik, O., and Lin, S. J.: Sources and distributions of dust aerosols simulated with the GOCART model, J. Geophys. Res., 106, 20225-20273, 2001.

Goudie, A. S. and Middleton, N. J.: Saharn dust storms: nature and consequences, Earth-Sci. Rev., 56, 179-204, 2001.

Jeong, M.-J., Tsay, S.-C., Ji, Q., Hsu, N. C., Hansell, R. A., and Lee, J.: Ground-based measurements of airborne Saharan dust in marine environment during the NAMMA field experiment, Geophys. Res. Lett., 35, L20805, doi:10.1029/2008GL035587, 2008.

Kaufman, Y. J., Tanre, D., Dubovik, O., Karnieli, A., and Remer, L. A.: Absorption of sunlight by dust as inferred from satellite and ground-based remote sensing, Geophys. Res. Lett., 28, 14791482, 2001.

Kim, M. K., Lau, K. M., Chin, M., Kim, K. M., Sud, Y. C., and Walker, G. K.: Atmospheric teleconnection over Eurasia induced by aerosol radiative forcing during boreal spring, J. Climate, 19, 4700-4718, 2006.

Lau, K. M., Kim, M. K., and Kim, K. M.: Asian monsoon anomalies induced by aerosol direct effects: the role of the Tibetan Plateau, Clim. Dynam., 26, 855-864, doi:10.1007/s00382-0060114-z., 2006.

Lau, K. M. and Kim, K. M.: How Nature Foiled the 2006 Hurricane Forecasts. EOS Trans. AGU, 88(9), 105-107, 2007a.

Lau, K. M. and Kim, K. M.: Cooling of the Atlantic by Saharan dust, Geophys. Res. Lett., 34, L23811, doi:10.1029/2007GL031538, 2007b.

Lau, K. M. and Kim, K. M.: Observational relationships between aerosol and Asian monsoon rainfall, and circulation, Geophys. Res. Lett., 33, L21810, doi:10.1029/2006GL027546, 2006.

Middleton, N. J. and Goudie, A. S.: Saharan dust: sources and trajectories, Trans. Inst. Brit. Geographers, 26, 165-181, 2001.

Miller, R., L. and Tegen, I.: Climate response to soil dust aerosols, J. Climate, 11, 3247-3267, 1998.

Miller, R. L., Tegen, I., and Perlwitz, J.: Surface radiative forcing by soil dust aerosols and the hydrologic cycle, J. Geophys. Res., 109, D04203, doi:10.1029/2003JD004085, 2004.

Moulin, C., Lambert, C. E., Dulac, F., and Dayan, U.: Control of atmospheric export from North Africa by the North Alantic Oscillation, Nature, 397, 691-694, doi:10.1038/42679, 1997.

Perlwitz, J., Tegen, I., and Miller, R. L.: Interactive soil dust aerosol model in the GISS GCM I. Sensitivity of the soil dust cycle to radiative properties of soil dust aerosols, J. Geophys. Res., 106, 18167-18192, 2001.

Propsero, J. M. and Lamb, P. J.: African droughts and dust transport to the Caribbean: Climate Change Implications, Science, 302, 1024-1027, 2003.
Ramanathan, V., Chung, C., Kim, D., Bettge, T., Buja, L., Kiehl, J. T., Washington, W. M., Fu, Q., Sikka, D. R., and Wild, M.: Atmospheric Brown Clouds: Impacts on South Asian Climate and Hydrological Cycle, PNAS, 102(15), 5326-5333, 2005.

Sokolik, L. and Golistsyn, G.: Investigation of optical and radiative properties of atmospheric dust particles, Atmos. Environ. Part A, 27, 2509-2517, 1993.

Solmon, F., Mallet, M., Elguindi, N., Giorgi, F., Zakey, A., and Konaré, A.: Dust aerosol impact on regional precipitation over western Africa, mechanisms and sensitivity to absorption properties, Geophys. Res. Lett., 35, L24705, doi:10.1029/2008GL035900, 2008.

Sud, Y. C. and Walker, G. K.: Microphysics of clouds with relaxed Arakawa-Schubert Scheme (McRAS). Part II: Implementation and performance in GEOS 2 GCM, J. Atmos. Sci., 56, 31213240, 1999.

Sud, Y. C. and Walker, G. K.: Influence of ice-phase physics of hydrometeors on moist convection. Geophys. Res. Lett. 30(14), 1758, doi:10.1029/2003GL017587, 2003.

Tegen, I. and Lacis, A.: Modeling of particle size distribution and its influence on the radiative properties of minaeral dust aerosols, J. Geophys. Res., 101, 19237-19244, 1996.

Volz, F. E.: Infrared optical constants for ammonium sulfate, Sahara dust, volcanic pumice and flyash, Appl. Optics, 12, 564-568, 1973.

Waliser, D. E., Lau, K. M., and Kim, J. H.: The Influence of Coupled Sea Surface Temperatures on the Madden-Julian Oscillation: A Model Perturbation Experiment, J. Atmos. Sci., 56, 333358, 1999.

Xue, Y., De Sales, F., Lau, K. M., et al.: Simulated West African Monsoon variability at different scales - the West African Monsoon Modeling and Evaluation Project (WAMME), First Model Intercomparison Experiment, Clim. Dynam., in review, 2009.

Yoshioka, M., Mahowald, N., Conley, A. J., Collins, W. D., Fillmore, D. W., Zender, C. S., and Coleman, D. B.: Impact of desert dust radiative forcing on Sahel precipitation: relative importance of dust compared to sea surface temperature variations, vegetation changes and greenhouse gas warming, J. Climate, 16, 14451467, doi:10.1175/JCLI4056.1, 2007.

Zhu, A., Ramanathan, V., Li, F., and Kim, D.: Dust plumes over the Pacific, the Indian and the Atlantic Oceans : Climatology and radiative impact, J. Geophys. Res., 112, D16208, doi:10.1029/2007JD008427, 2007. 